NBER WORKING PAPER SERIES

THE WELFARE COST OF UNCERTAINTY IN POLICY OUTCOMES

\author{
Edward Schlee \\ V. Kerry Smith \\ Working Paper 22864 \\ http://www.nber.org/papers/w22864 \\ NATIONAL BUREAU OF ECONOMIC RESEARCH \\ 1050 Massachusetts Avenue \\ Cambridge, MA 02138 \\ November 2016, Revised January 2020
}

The views expressed herein are those of the authors and do not necessarily reflect the views of the National Bureau of Economic Research.

NBER working papers are circulated for discussion and comment purposes. They have not been peer-reviewed or been subject to the review by the NBER Board of Directors that accompanies official NBER publications.

(C) 2016 by Edward Schlee and V. Kerry Smith. All rights reserved. Short sections of text, not to exceed two paragraphs, may be quoted without explicit permission provided that full credit, including $(\odot$ notice, is given to the source. 
The Welfare Cost of Uncertainty in Policy Outcomes

Edward Schlee and V. Kerry Smith

NBER Working Paper No. 22864

November 2016, Revised January 2020

JEL No. H41,Q50,Q51

\begin{abstract}
This paper proposes a simple index of the welfare significance of uncertainty in the public goods resulting as policy outcomes. Our measure is the ex ante compensation an individual would require to accept an uncertain level of service compared to receiving the expected value of the distribution of possible values for that service. Our compensation measure is a function of the coefficient of relative risk aversion, the variance in the measure of environmental service associated with policy and relevant for the individual, and a set of conventional parameters that describe the properties of nonmarket benefit measures under conditions of certainty. We would expect that the inverse virtual price elasticity of the for the environmental service and the square of the coefficient of relative variation are the primary factors influencing the size of our compensation index.
\end{abstract}

Edward Schlee

Arizona State University

ed.schlee@asu.edu

V. Kerry Smith

Department of Economics

W.P. Carey School of Business

P.O. Box 879801

Arizona State University

Tempe, AZ 85287-9801

and NBER

kerry.smith@asu.edu

An online appendix is available at http://www.nber.org/data-appendix/w22864 


\title{
The Welfare Cost of Uncertainty in Policy Outcomes
}

\author{
Edward E. Schlee and V. Kerry Smith
}

Revised 9/5/2019

\section{Introduction}

Most of the literature on policy design under uncertainty since Weitzman's [1974] classic paper considers how uncertainty about pollution control costs, that is assumed known to firms but unknown to policymakers, affects instrument choice. This approach to modeling the effects of uncertainty is incomplete. When there is uncertainty about how firms will respond to a policy we should expect the realized environmental quality will also be uncertain regardless of the instrument that is selected. None of the benefit analyses for evaluating a new policy take account of the fact that when the outcomes of that intervention are uncertain, the benefit measures attributed to the policy will be different from what are conventionally used in benefit cost analyses.

A recent example of the importance of uncertainty in policy outcomes can be found in Cropper et al.’s [2017] comparison of the estimates from EPA's Regulatory Impact Analysis (RIA) of the 1998 Cluster Rule, designed to reduce hazardous air and water pollutants from pulp and paper mills, with what was realized. They note that the RIA's predicted reductions in chloroform were largely achieved, but other toxic air pollutants experienced reductions that were half of what was predicted and there was no reduction in PM10 ${ }^{1}$. More generally, when analysts consider the outcomes of policy using monitored levels of air pollution they find significant variability in what is realized. For example, Brajer et al. [2010] note that between 2005 and 2007 in Southern California the eight hour ozone standard was exceeded about one third of the time somewhere in the region, despite an aggressive program of regulation that was expected to assure the standard would be met.

\footnotetext{
${ }^{1}$ Cropper et al. [2018] also describe differences between ex ante and ex post outcome with the NOx Budget program.
} 
Fowlie and Muller [2017] have also documented how differences in what is known about abatement costs ex ante versus what is realized ex post can impact the welfare properties attributed to different policy instruments. Using Muller's [2011] AP2 model, along with engineering estimates of source specific and technology specific abatement costs, they compare differentiated tradeable emission permits with undifferentiated permits for EPA's $\mathrm{NO}_{\mathrm{x}}$ Budget Program (NBP) ${ }^{2}$. Their analysis assumes perfect compliance by the electric generating plants subject to the rule. Even with this ideal adherence to the regulation, they find the difference between plants' ex post observed compliance choices and the decisions that would minimize the ex ante compliance costs were sufficient to undermine any theoretical preference for differentiated emission trading policies. When regulators do not have knowledge of the intra-source distribution of marginal costs, policies based on ex ante engineering estimates of them can lead to markedly different outcomes than what is realized ex post. While the Fowlie and Muller analysis uses a simple description of the damage function for $\mathrm{NO}_{\mathrm{x}}$, the AP2 model does incorporate estimation uncertainty for the key parameters leading to the model's marginal damage estimates. All of the benefit measures in these analyses assume people do not recognize the potential for uncertainty in the outcomes of policy ${ }^{3}$. This assumption is inconsistent with what has been learned from several studies of households’ avoidance behavior. Graff Zivin and Neidell [2009], for example, found the

\footnotetext{
${ }^{2}$ AP2 is an integrated assessment model that connects emissions of five common air pollutants (nitrogen oxides, sulfur dioxide, fine particulate matter, ammonia, and volatile organic compounds) to estimates of ambient concentrations, exposures to air pollutants, physical effects, and monetary damages. This last step is as a reduced form computation. See Baker et.al.[2018] for a comparison of the AP2 model to alternative reduced form models used to compute the physical effects and monetary damages from emissions of these air pollutants.

${ }^{3}$ Chavas and Mullarkey [2002] provide the most comprehensive effort to unify the literature on ex ante welfare measures under uncertainty. Using a two period model that distinguishes both the timing of decisions and the resolution of uncertainty, these authors describe how the contributions of information, risk aversion, and policy can be distinguished in ex ante welfare measures. Their risk measure is a conditional measure of risk aversion. It is the premium that an individual would pay ex ante to have knowledge of the expected values for both periods' sources of uncertainty. In this context, choices could be made under conditions that reflect compensation for resolution of the first period's uncertainty, but with only the information a risk neutral decision maker would need for private choices. Policies are defined so that they focus on changes in services that are not subject to private choice. These services can influence the choices of private consumption goods and thus would affect the decomposition of the ex ante compensation into the conditional value of risk and the individual's valuation for the policy. They do not consider uncertainty in the policy outcomes as we treat it here.
} 
behavioral dynamics of responses to smog alerts depend on the pattern of alerts and can be interpreted as a response to the uncertain air quality conditions ${ }^{4}$.

We develop a simple index of the bias arising when the environmental quality improvement from policy is uncertain. Two cases are considered. The first assumes the baseline level of environmental quality is not random and that only the level of quality realized with a new policy is random. The second case treats both the baseline and level arising from policy as random.

Our analysis develops a second order approximation for a welfare measure that is interpreted differently depending on the description of the policy context. For the first case, where only the outcome of policy is uncertain, our measure is an approximation for the certainty equivalent. We can distinguish two parts of this measure. The first is the second order approximation for the Hicksian equivalent surplus for a certain (non-stochastic) increase in the environmental service associated with a policy. The second is a term reflecting the adjustment a consumer would require to this conventional measure due to the effects of uncertainty in the outcome of that policy. When there is uncertainty about both the baseline and the outcome from policy we define an option price. Our expression is a second order approximation that distinguishes the conventional surplus measure and includes the term reflecting the uncertainty which, in this case, depends on the magnitude of the variance in baseline compared to the variance in the post policy conditions. The general form of our index is not affected by the definition we adopt for the welfare measure -whether certainty equivalent or willingness to pay in the case of one random variable or the equivalent and compensating definitions for the option price when both baseline and policy outcomes are random variables. There is the conventional difference between equivalent and compensating definitions and the associated welfare measures for our cases as a result of income effects.

This extension is important because it distinguishes risk aversion arising from uncertainty in the public good from risk aversion arising from income uncertainty. With non-separable preferences, the ability to adjust the consumption levels of private goods in response to

\footnotetext{
${ }^{4}$ Bäer et al. [2014] found the correlation between weather conditions and pollution affects the ability to detect consistent averting responses to pollution. However, the sensitive groups (children and older adults) do reduce time outdoors during high pollution episodes.
} 
different levels of the quasi-fixed environmental service affects how the two types of aversion are related. Our compensation measure describes how this connection, together with private adaptation, influences the importance of uncertainty in the amount of the environmental public good. In addition, the assumption of non-separable preferences allows measureable features of individual demand to be used to characterize individual attitudes toward uncertainty in the amount of the quasi-fixed, environmental good.

To offer a "back of the envelope" estimate of what our index would imply for the potential importance of uncertainty in what environmental policy is able to provide, we use the case of a certain baseline and an uncertain policy outcome. We begin with the CurrieNeidell [2005] estimates for the within zip code/month variance in ozone for Southern California, together with the reduction in the eight hour ozone concentrations as our indication of an air quality policy outcome. Our index of the importance of uncertain environmental services uses a measure of compensation relative to the amount of virtual income due to the improved level of the environmental good. With approximate estimates of demand and income elasticities for environmental services as well as for the coefficient of relative risk aversion from the literature, our index of the importance of uncertainty would call for reducing benefit measures for this improvement in ozone relative to this contribution to virtual income, by approximately ten percent.

Section two describes how the benefits from improvements in environmental quality are commonly estimated and provides a selective summary of the past treatment of uncertainty in these analyses. The third section derives our index of the importance of people's responses to uncertainty in environmental services. The last section sketches the details for our back-ofthe-envelope calculation. It also discusses some next steps for considering how the uncertainty in policy outcomes can be included in the benefits measures used in benefit cost analysis.

\section{Context}

When benefit cost analyses are prepared to evaluate environmental policies the constraints of time and resources usually require simplified estimation strategies. Conventional economic theory would define the benefits in terms of an indirect utility 
function. That is, given a quasi-concave direct utility function, with $q$ designating the amount of an environmental service available to an individual as a quasi-fixed commodity, then the compensation, $\mathrm{A}$, an individual would require to forego an improvement in $q$ from $q_{0}$ to $q_{1}$ is defined in equation (1).

$$
V\left(q_{0}, p, m+A\right)=V\left(q_{1}, p, m\right)
$$

$V(m, p, q)$ designates the indirect utility function. Individual income is represented by $m$ and a vector of prices for goods and services with $p$.

Often benefit cost analyses would approximate $A$ using an estimate of the unit benefits, $b$, as in equation $(1 \mathrm{a})^{5}$.

$$
\text { (1a) } \hat{A}=b \cdot\left(q_{1}-q_{0}\right)
$$

The connection between $A$ and $\hat{A}$ has been discussed extensively in the literature on benefits transfer, usually within a willingness to pay framework. One simple way to motivate a link between $A$ and $\hat{A}$ is to replaces the left side of equation (1) with a first order Taylor approximation in income around the point defined by $\left(q_{0}, m, p\right)$. This relationship is given in equation (2).

$$
V\left(q_{0}, p, m+A\right) \approx V\left(q_{0}, p, m\right)+V_{m}\left(q_{0}, p, m\right) \cdot(m+A-m)
$$

Replacing the right side of (1) with a first order expansion in $q$ around ( $\left.m, p, q_{0}\right)$ and substituting (2) for the left side of (1) yields (3) as an approximation for $A$. It also offers a specific interpretation of the measure that should be used for $b$ from equation (1a). It should be the virtual price for $q,\left(V_{q} / V_{m}\right){ }^{6}$

\footnotetext{
${ }^{5}$ Most of the benefit cost analyses prepared as part of evaluating new policies assume the changes under study are small in relationship to the overall economy. As a result general equilibrium (GE) effects are not considered. Smith and Zhao [2019] discuss an index for gauging when GE effects need to be considered. Our approach could be extended to this setting. However, the current state of the art in benefit estimation limits our ability to characterize both the nature of GE effects and the potential for uncertainty influencing GE outcomes. So we consider this issue one for future research when these information gaps improve.

${ }^{6}$ We would get the same result with $V_{q} / V_{m}$ evaluated at $q_{1}$ instead of $q_{0}$ had we used a willingness to pay framework. For the most part, applications are more likely to be able to estimate the marginal value at the initial quality level $\left(q_{0}\right)$, not the one expected to arrive from the policy change.
} 
(3) $\hat{A}=\frac{V_{q}}{V_{m}} \cdot\left(q_{1}-q_{0}\right)$

When we assume that the effects of policy are uncertain, then the definition for either the compensation or willingness to pay for a policy needs to be reconsidered. An early recognition of these issues by Foster and Just [1989] considered a situation when consumers recognize that quality is uncertain and make commitments to purchase private goods and services based on their initial beliefs about quality ${ }^{7}$. To develop measures for the benefits from information policies, the authors consider a thought experiment. They ask: what would be the implications of recognizing that the beliefs about quality were incorrect? They develop a benefit measure for the new information (whether good or bad "news" about the level of quality) in terms of the adjustments to the expenditures on private goods in response to new information, “correcting old beliefs”. Measures of the cost of ignorance are derived by specifying a demand structure (and implied quasi indirect utility function) that allows the derivation of the price required for the good with new information about quality in order to assure the original consumption of that good was maintained. ${ }^{8}$ More recently, Shafran [2014] has considered a situation with uncertainty in the results of a policy. Using the equivalent definition of the option price, along with estimates for an individual's equivalent variation for quality changes that are not random, along with estimates for the coefficient of relative risk aversion, he shows how information about Hicksian equivalent surplus for nonrandom changes can be adapted to derive the correct option price measure.

Our analysis describes how an index of the importance of uncertainty can be derived within a general setting that distinguishes the second order approximation for a certain change in environmental quality from the adjustment required to take account of uncertainty in the policy outcomes. This decomposition is derived for the two cases we consider - when the

\footnotetext{
${ }^{7}$ Quality in their case is associated with a private good. Because it is assumed to make a separate contribution to individual preferences, their analysis is directly relevant to situations where environmental quality affects the value of private goods. For example the water quality of a lake would influence households' decisions to use the lake for their recreation.

${ }^{8}$ Compensating surplus is then the difference in the expenditures required to realize the original utility level with the new and old information and associated prices adjusted by the difference in the expenditures required to purchase the original amount of the private good at the old and "new" price. This new price is what would be required for the individual to purchase the original consumption level of the private good with the new information.
} 
policy outcome is treated as random and when both the baseline and the policy outcomes are random.

\section{Risk Aversion and Compensation for Policy Uncertainty}

\section{a. Uncertainty in Environmental Quality Outcomes of Policy}

Our goal is to develop an index of the effects of uncertainty in a nonmarket environmental service while holding prices and income constant. The first case considers a situation where we assume the baseline level of environmental quality is not a random variable and the level of quality resulting from the policy is. We begin with the definition of a certainty equivalent measure, $C$. This is the compensation an individual would require to be indifferent between a certain baseline level of environmental quality ( $\left.q_{0}\right)$ with $C$ compared to a random level of quality that has a higher mean value of $\bar{q}_{1}$, as defined in equation (4) ${ }^{9}$.

$$
E[V(q, p, m)]=V\left(q_{0}, p, m+C\right)
$$

To develop our index and connect the result to measures of individual risk aversion, we begin by defining the random environmental quality in equation (5).

$$
\text { (5) } \quad q=q_{0}+t \varepsilon
$$

The term $\varepsilon$ is random with distribution function $F_{1}(\varepsilon)$, expected value of $\left(\bar{q}_{1}-q_{0}\right)$, and a variance of $\sigma_{\varepsilon}^{2}$. The term $t$ defines an index that allows the impact of the policy change leading to a random outcome for environmental quality that varies in magnitude. Our certainty equivalent measure, $C$, will be a function of the parameters describing the distribution for $q$. This use of this certainty equivalent, $C$, is a bit different from the usual definition (see Gollier [2001] p.21, equation (2.3)). In the conventional case, we are usually considering uncertainty in wealth (or income) and defining the certainty equivalent in the same units. Here the uncertainty is in terms of a non-market service and the certainty equivalent is in terms of a market good, our numeraire. As a result, it is possible to describe

\footnotetext{
${ }^{9}$ See note \#4 above for further discussion.
} 
how the degree of substitution between market and nonmarket goods, reflecting the ability to adapt, will influence measures for $C$.

Taking a second order expansion of $C$ in terms of $t$, and expressing the derivatives of $C$ in terms of the derivatives of the indirect utility function, we can link our approximation to estimated parameters in the literature. Equation (6) replaces the left side of (4) with the definition, using $F_{1}(\varepsilon)$ to describe the uncertain outcome of the policy intervention and its implications for the resulting $q$.

$$
\int V\left(q_{0}+t \varepsilon, p, m\right) d F_{1}(\varepsilon)=V\left(q_{0}, p, m+C(t)\right)
$$

Differentiating both sides of (6) with respect to $t$ and evaluating the expression at $t=0$, we have (6a) which confirms that $C^{\prime}(0)$ uses the virtual price or shadow value for $q$, with the partial derivatives of $V($.$) evaluated at \left(q_{0}, p, m\right)$, to approximate the benefits from the change in environmental quality associated with the mean level of $q$ with the policy, compared to the non-random baseline or $\left(\bar{q}_{1}-q_{0}\right)$.

$$
\text { (6a) } C^{\prime}(0)=\frac{V_{q}}{V_{m}}\left(\bar{q}_{1}-q_{0}\right)=b\left(\bar{q}_{1}-q_{0}\right)
$$

In what follows we will use $b$ to designate the virtual price of $q$. In practice, an average estimate of consumer surplus per unit change in the measure of environmental quality is often used to provide an approximate measure of $b$.

Taking a second derivative of equation (6) with respect to $t$, using our assumptions about the properties of $\varepsilon$ and evaluating the result at $t=0$, we have an expression for $C^{\prime \prime}(0)$ as given in equation $(7)^{10}$.

\footnotetext{
${ }^{10}$ Differentiating equation (6) twice with respect to $t$, we have:

$\int V_{q q} \varepsilon^{2} d F_{1}(\varepsilon)=V_{m} C^{\prime \prime}(t)+V_{m m} C^{\prime}(t)$. By evaluating the partial derivatives of $V(q, p, m)$ at $t=0$ we assure consistency in the point of evaluation of the functions on each side of the equations defining our welfare
} 
(7) $\quad C^{\prime \prime}(0)=\frac{V_{q q}}{V_{m}}\left(\sigma_{\varepsilon}^{2}+\left(\bar{q}_{1}-q_{0}\right)^{2}\right)-\frac{V_{m m}}{V_{m}} b^{2}\left(\bar{q}_{1}-q_{0}\right)^{2}$

Now using (6a) and (7) in a second order expansion in terms of , with the derivatives evaluated at $t=0$, we develop an approximation that allows us to separate how our expression for the certainty equivalent includes both the conventional benefit measure (associated with a certain change in environmental quality from $q_{0}$ to $\bar{q}_{1}$ ) and an adjustment that takes account of the uncertainty in the level of environmental quality that the policy intervention produces. As we noted earlier, our certainty equivalent is being defined for an environmental service, not a factor that is defined in monetary terms such as income or wealth and affects individual wellbeing. Our goal in developing this approximation for $C$ is to use the properties of an individual's preference function to provide links between measures of the importance of variation in environmental services and conventional measure of risk aversion.

(8) $C(t) \approx C(0)+C^{\prime}(0) t+\frac{1}{2} C^{\prime \prime}(0) t^{2}$

Using equations (6a) and (7) in this second order approximation for $C(t)$ given in (8), we have equation (8a):

$$
\begin{gathered}
\text { (8a) } C(t) \approx b\left(\bar{q}_{1}-q_{0}\right) t+\frac{1}{2}\left(\sigma_{\varepsilon}^{2}+\left(\bar{q}_{1}-q_{0}\right)^{2}\right) b \frac{V_{q q}}{V_{q}} t^{2} \\
-\frac{1}{2} \frac{V_{m m}}{V_{m}} b^{2}\left(\bar{q}_{1}-q_{0}\right)^{2} t^{2}
\end{gathered}
$$

We can use the properties of the virtual price function to provide an alternative expression for $C$ that is more directly linked to parameters that can be estimated. Equations (9a) and (9b) provide the link between the derivatives of $b_{q}$ and $b_{m}$ and the indirect utility function.

measures. Using the properties of $\varepsilon$, namely, $E\left(\varepsilon^{2}\right)=\sigma_{\varepsilon}^{2}+\left(\bar{q}_{1}-q_{0}\right)^{2}$, we have the expression in equation (7). See the online appendix for the details of the derivation. 
(9a)

$$
b_{q}=\frac{V_{q q}}{V_{m}}-b \frac{V_{q m}}{V_{m}}
$$

$$
b_{m}=\frac{V_{m q}}{V_{m}}-b \frac{V_{m m}}{V_{m}}
$$

So the expression $b \cdot b_{m}+b_{q}=\frac{V_{q q}}{V_{m}}-b^{2} \frac{V_{m m}}{V_{m}}$ allows equation (8a) to be written in a form that is more directly recognized as comparable to a Slutsky-like equation for an inverse demand function (see Anderson [1980] p.288, equation(18)).

$$
\text { (10) } C(t) \approx b\left(\bar{q}_{1}-q_{0}\right) t+\frac{1}{2}\left(\bar{q}_{1}-q_{0}\right)^{2}\left(b_{q}+b \cdot b_{m}\right) t^{2}+\frac{1}{2} b \frac{V_{q q}}{V_{q}} \sigma_{\varepsilon}^{2} t^{2}
$$

The first two terms in (10) expression are from a second order Taylor series approximation for the welfare measure in terms of the quasi-fixed good and analogous to what McKenzie and Pearce [1982] use for the case of a welfare measure for price changes (see their equation (6)). The last term is our index for the adjustment due to policy uncertainty.

We can re-write this last term by introducing $q_{0}$ into the numerator and denominator. The term ( $-q_{0} V_{q q} / V_{q}$ ) is now recognized as the coefficient of relative risk aversion for $q$, denoted by $r_{q}$. It describes the curvature of the preference function in terms of the nonmarket environmental service ${ }^{11}$. Focusing on this third term, now labeled as $c$, (to distinguish it from the approximation for the certainty equivalent $C$ ), we have equation (11).

$$
c \approx-\frac{1}{2} b r_{q} \frac{\sigma_{\varepsilon}^{2}}{q_{0}}
$$

\footnotetext{
${ }^{11}$ The derivatives of $V(q, p, m)$ are evaluated at $q_{0}$. This assumption is based on the assumption that the information for evaluating policies describes consumer behavior under the baseline conditions.
} 
With some further substitutions, we can connect our index to concepts with available estimates from applications. Using (9a) and (9b) we can write the income elasticity of the virtual price of $q$ in (12)

$$
\frac{m}{b} \cdot \frac{\partial b}{\partial m}=\frac{m V_{q m}}{V_{q}}-\frac{m V_{m m}}{V_{m}}
$$

Now we can express the relative risk aversion coefficient for $q, r_{q}$ in terms of the income elasticity for $b$, the relative risk aversion coefficient for risks to income $r$, defined as $r=$ $\left(-m \frac{V_{m m}}{V_{m}}\right)$, and $\theta$ the inverse "price” elasticity for $q$ as in equation (13).

$$
r_{q}=s \cdot(r-n)+\theta
$$

where: $s=$ the share of income that would be associated with the virtual expenditures on $q$.

$$
\begin{aligned}
& s=\frac{b q_{0}}{m} \\
& b=\text { virtual price for } q ; \\
& \theta=-\frac{\partial b}{\partial q} \cdot \frac{q_{0}}{b} \\
& n=\frac{\partial b}{\partial m} \cdot \frac{m}{b}
\end{aligned}
$$

Weak complementarity and the Willig [1978] condition imply that $n$ is equal to the income elasticity of the weak complement (Palmquist [2005]) ${ }^{12}$. As a result, for those cases where $q$ has a private good that is a weak complement, equation (13) can be re-written using this income elasticity, $\xi$, for $x$ a private good that is assumed to be a weak complement to $q$ as equation (14).

$$
\begin{aligned}
& r_{q}=s(r-\xi)+\theta \\
& \text { with } \xi=\frac{\partial x}{\partial m} \cdot \frac{m}{x}
\end{aligned}
$$

\footnotetext{
${ }^{12}$ For a graphical analysis explaining how weak complementarity and the Willig condition can be related to equivalent changes in the weak complement's price see Smith and Banzhaf [2006].
} 
To our knowledge $r_{q}$ has not been estimated. Thus equation (14) allows our index of the effects of uncertainty in $q$ to be expressed in terms of measures of preferences that have been estimated in a variety of contexts. As we noted earlier, it is also important to acknowledge all measures of risk aversion depend on what is allowed to adjust. For the case of environmental quality this is especially important because we usually label these adjustments in expenditures on private goods and services or allocations of time as adaptation. One can readily demonstrate that bounds for the measures of aversion depend on the extent of adaptation. Measures of aversion are smallest when all private goods are allowed to adjust and can be expected to be progressively larger as adjustment options are restricted ${ }^{13}$. Substituting for $r_{q}$ using (14) into (11) we can express $c$ relative to the virtual expenditures for $q$ evaluated at the expected value as in equation (15).

$$
\frac{c}{b q_{0}} \approx-\frac{1}{2}(s(r-\xi)+\theta) \frac{\sigma_{\varepsilon}^{2}}{q_{0}^{2}}
$$

Our derivation also provides a description of the relationship of our index to a second order approximation of the compensation measure for a certain change in $q$ and the first terms in equation (10) is the conventional measure of benefits used in practice.

\section{b. Uncertainty in Environmental Quality Before and After Policy}

To treat both the baseline and policy generated levels for $q$ as random we must introduce a new measure of the welfare change for a policy. Instead of a certainty equivalent we use the equivalent surplus version for the option price (OP), as defined in equation (17).

$$
\int V\left(\bar{q}_{0}+t \varepsilon, p, m\right) d F_{1}(\varepsilon)=\int V\left(\bar{q}_{0}+t v, p, m+O P(t)\right) d F_{0}(v)
$$

In this equation $F_{0}(v)$ is the distribution function for $v$ (the error added to the baseline, average environmental quality, $\bar{q}_{0}$ ) to allow for uncertainty in the initial level of quality. Now we re-define $E(\varepsilon)=\bar{q}_{1}-\bar{q}_{0}$. We assume $\mathrm{E}(v)=0$ and the variance in $v$ is $\sigma_{v}^{2}$. Using the

\footnotetext{
${ }^{13}$ Assume there are $\mathrm{N}$ private goods, described as $x=(y, z)$, with $y$ a single good and $z$ a vector of $N-$ 1 goods. Comparing the absolute magnitude of measures of an individual's aversion to variation in $q$, we can establish that: $-\frac{V_{q q}}{V_{q}}(\bar{q}) \leq-\frac{U_{q q}}{U_{q}}(\bar{q}, \bar{z}) \leq-\frac{u_{q q}}{u_{q}}(\bar{x}, \bar{q}) \cdot u(x, q)$ is the direct utility function and $U(\bar{q}, \bar{z})$ is defined as $\max _{p_{y} y+p_{z} \bar{z} \leq m} u(y, \bar{z}, \bar{q})$. The bars designate fixed levels of each argument. See the Appendix, section E for the details of our argument.
} 
same basic logic as with the case of a single random variable, we can define a second order approximation for $O P(t)$ in terms of $t$ and express $O P^{\prime}(0)$ and $O P^{\prime \prime}(0)$ in terms of partial derivatives of the indirect utility function, as given in (18a) and (18b).

$$
\begin{gathered}
(18 a) O P^{\prime}(0)=\frac{V_{q}}{V_{m}}\left(\bar{q}_{1}-\bar{q}_{0}\right)=b\left(\bar{q}_{1}-\bar{q}_{0}\right) \\
(18 b) O P^{\prime \prime}(0)=\frac{V_{q q}}{V_{m}}\left(\sigma_{\varepsilon}^{2}-\sigma_{v}^{2}\right)+\frac{V_{q q}}{V_{m}}\left(\bar{q}_{1}-\bar{q}_{0}\right)^{2} \\
-\frac{V_{m m}}{V_{m}} b^{2}\left(\bar{q}_{1}-\bar{q}_{0}\right)^{2}
\end{gathered}
$$

Once again using the expression $b \cdot b_{m}+b_{q}=\frac{V_{q q}}{V_{m}}-b^{2} \frac{V_{m m}}{V_{m}}$ we can re-write (18b) as (18c).

$$
\begin{gathered}
(18 c) O P^{\prime \prime}(0)=\left(b \cdot b_{m}+b_{q}\right)\left(\bar{q}_{1}-\bar{q}_{0}\right)^{2} \\
+\frac{V_{q q}}{V_{m}}\left(\sigma_{\varepsilon}^{2}-\sigma_{v}^{2}\right)
\end{gathered}
$$

Now substituting these terms into the second order approximation for the option price function with the derivatives of the function evaluated at $t=0$ (comparable to what we did with the certainty equivalent) we have (19).

$$
\text { (19) } \begin{aligned}
& O P(t) \approx b\left(\bar{q}_{1}-\bar{q}_{0}\right) t+\frac{1}{2}\left(\bar{q}_{1}-\bar{q}_{0}\right)^{2}\left(b_{q}+b b_{m}\right) t^{2} \\
+ & \frac{1}{2} \frac{V_{q q}}{V_{q}} b\left(\sigma_{\varepsilon}^{2}-\sigma_{v}^{2}\right) t^{2}
\end{aligned}
$$

The last term in equation (19) has a comparable form to that in equation (10). However it now considers the difference in the variance in the error for baseline conditions versus what characterizes the situation with the policy. Using comparable substitutions, we have our index of the importance of behavioral responses to uncertainty (labeled as $c^{*}$ ) expressed in terms of 
the magnitude of the variance in environmental quality after the policy compared to the variance in conditions before, as in (20)

$$
\text { (20) } \frac{c^{*}}{b \bar{q}_{0}} \approx-\frac{1}{2}(s(r-\xi)+\theta) \frac{\left(\sigma_{\varepsilon}^{2}-\sigma_{v}^{2}\right)}{\bar{q}_{0}^{2}}
$$

As we demonstrate in the Appendix, the adjustment for uncertainty would not change had we adopted a compensating surplus (or a willingness to pay) framework to define the option price (labeled as $W$ ). The final result in this case is given in equation (21).

$$
\begin{aligned}
(21) W(t) \approx & b\left(\bar{q}_{1}-\bar{q}_{0}\right) t+\frac{1}{2}\left(\bar{q}_{1}-\bar{q}_{0}\right)^{2}\left(b_{q}-b b_{m}\right) t^{2} \\
& -\frac{1}{2}(s(r-\xi)+\theta) b \frac{\left(\sigma_{\varepsilon}^{2}-\sigma_{v}^{2}\right)}{\bar{q}_{0}} t^{2}
\end{aligned}
$$

The virtual price flexibility, $\theta$, can be related to the income elasticity of demand for environmental services relative to a composite elasticity of substitution between these services and a Hicksian composite good for all private goods that each individual consumes ${ }^{14}$. While we might expect that the income elasticity of demand for environmental services is greater than unity, there is also some indirect evidence indicating for some resources it may be less than one (see Kriström and Riera [1996]).

The logic underlying the expectation for values greater that one assumes that higher demands are associated with individuals with higher incomes. If we assume the income elasticity is unity, this adaptation of Chavas' logic would imply that we consider whether private goods provide adequate substitutes for the environmental services that are likely to be subject to policy uncertainty. If they do not have good substitutes, then we would expect the price flexibility (in absolute magnitude) to be appreciably greater than one. So a range of estimates from 1 to 3 for $\theta$ could seem reasonable. This parameter is likely the dominant factor in gauging approximate values for our index of the importance of policy uncertainty, when the baseline level of environmental quality is assumed non-random.

\footnotetext{
${ }^{14}$ The relationship can be derived from Chavas [1984] analysis of mixed demands (see Smith [1992] equation (2)).
} 
Most policy assessments imply the virtual expenditures for environmental services would be small and are likely under $3 \%$ of virtual income ${ }^{15}$. Selecting a value or range of values for the coefficient of relative risk aversion is potentially more controversial. Empirical assessments have yielded a wide range of values, some as large as 4 or $5^{16}$. Recent work in the context of risks to wealth would support using estimates at the high end of this range when we consider aversion to income losses ${ }^{17}$. By contrast, Chetty’s [2006] bound for r, with modest levels of complementarity between consumption and leisure, implies a value for the coefficient of relative risk aversion of 0.97 with a range of values at the bottom end of what the literature would imply for risks to income --from 0.30 to 2.30. The composite of this research would suggest that using the high end of Chetty's range would be conservative.

Our compensation index for the importance of uncertainty needs one more parameter either the "price" flexibility of income $(n)$, using equation (14) or the income elasticity of demand for a private good $(\xi)$ known to be a weak complement to the non-market service, using equation (15). There are estimates of both in the literature (see Phaneuf and Smith [2005] for the case of recreation). None of these estimates for either $n$ or $\xi$ would exceed the upper limit from Chetty's range for $\mathrm{r}$ and certainly not for the majority of the other literature using either $n$ or $\xi$. Thus, we would expect that $\theta$ and the relative variance in $q$ are the primary factors influencing the size of $\left({ }^{c} / b \bar{q}_{0}\right)$.

Developing a range of empirical examples for the approximate magnitude of $\left({ }^{c} / b \bar{q}_{0}\right)$ is difficult because we are usually confined to proxy variables as our measures for $\mathrm{q}$ and empirical studies do not always present measures for the variability in these proxies over time or geography. Fortunately, Currie and Neidell's [2005] results using weekly ozone and PM10 (particulate matter 10 microns or less) readings at the zip code level in California for 11 years

\footnotetext{
${ }^{15}$ Virtual income is the sum of monetary income plus the virtual expenditures (i.e. virtual price of the quasi fixed service times the amount of the service with the baseline or reference allocation of resources). Carbone and Smith [2008] provide a sensitivity analysis of the effects of the assumption about this virtual share for partial and general equilibrium measures of the excess burden of taxes that would affect nonmarket environmental services.

${ }^{16}$ See Meyer and Meyer's [2005] summary reports adjusted estimates between 0.8 and 2.4 for wealth and 2.8 to 7 for consumption which is likely more relevant for our income measure. See their Table 2.

17 See Cohen and Einav [2007].
} 
provide what we need ${ }^{18}$. Considering first the results for ozone, our approximate estimates of the remaining parameters would imply that a "back of the envelope" estimate of the welfare importance of the uncertainty in ozone of about two percent. Comparing this estimate with an estimate of $\hat{A}$ for the change in ozone from 1989 to 2000 relative to $b q_{1}$. This example interprets the change in ozone from 1989 to 2000 as $\left(\bar{q}_{1}-q_{0}\right)$. Our ratio would be 227 . So uncertainty would call for reducing conventional benefit measures compared to $b q_{1}$ by ten percent. The same exercise for PM10 would imply about a twelve percent reduction to the corresponding $\hat{A}$ compared to the equivalent $b q_{1}$. Of course, the importance of our index of uncertainty will vary with the measure for $q$ and the context. As we discuss in footnote \#13 above, our measure of the aversion to uncertainty in environmental conditions will also depend on whether other goods can be adjusted. The comparison we discuss in that note provides a direct example of the potential importance of private (and public) adaptation to environmental uncertainty. It illustrates why the ability to adapt with private goods affects the adjustment for uncertainty. Our sample calculations would change with different assumptions about the extent of adaptation. When adjustment is not possible or very costly, uncertainty in the outcomes of environmental policy can be important to the benefits we attribute to proposed policies.

\section{Implications}

Benefit cost analyses of proposed environmental policies assume the regulations being evaluated "work". That is, they assume the new rules yield, with certainty, the improvements in the specific dimensions of environmental quality that are being assessed. As we noted earlier, there are many examples of discrepancies between the anticipated outcomes of regulatory programs and what is actually realized. This observation is hardly surprising. Indeed, analysts use these experiences to enhance our understanding of the rulemaking process.

\footnotetext{
${ }^{18}$ Reductions in ambient concentrations of pollution are commonly used as a proxy for air quality. We follow this logic and use for our example the variance in ambient concentrations as a proxy for $\sigma_{\varepsilon}^{2}$.
} 
People adapt to uncertainty in environmental conditions. We selected one example for the case of air quality. There are many other empirical examples where individuals recognize uncertainty in environmental conditions and adjust their behavior - whether in response to warnings about food products or drinking water, weather and outdoor recreation, or indoor air pollution ${ }^{19}$. The possibility that policy measure may change this uncertainty -increasing the variability in environmental conditions or decreasing it has been overlooked in the literature. Once we acknowledge people adapt then the benefit measures we attribute to these policies need to reflect this uncertainty.

Of course, each regulatory program will be different. Realized outcomes from the new rules depend on the actual conditions of those facilities responsible for the emissions. They also depend on the implementation process and the natural systems that affect the dispersal of emissions and the resulting ambient air quality. To the extent one policy leads to recognizable differences in the uncertainty likely for environmental services provided by that program, the benefit estimates should be reduced to reflect it. Our index of compensation for risk provides a first step in acknowledging that people recognize uncertainty in environmental quality. These responses imply that when benefits are attributed to new policies they should be reduced to take account of the uncertainty in what they can actually deliver.

Our examples were presented in relative terms (i.e. compared to approximate measures for $b q_{1}$ ) deliberately because each component of the example uses proxy measures for quality and realistic examples will require careful delineation of the estimates underlying $r_{q}$ for each environmental resource and a closer link to the specific policies under consideration. Ideally the development of the index will motivate greater effort to consider how the variance in environmental quality should be measured -- whether over locations within the same air shed (or river basin) or over time for a given location -- as well as the economic parameters that are components of $r_{q}$.

\footnotetext{
${ }^{19}$ Cases involving information disclosures do not exactly match our framework. They offer indirect evidence that consumers react to uncertainty in environmental conditions that affect goods and services they consume. For an example involving drinking water see Graff Zivin, Neidell, and Schlenker [2011]; for one involving consumption advisories see Shimshack, Ward, and Beatty [2007]; for indoor air pollution see Smith, Desvousges, and Payne [1995]; and for weather and cycling see Chan and Wichman [2018].
} 


\section{References}

Anderson, Roland W. 1980. "Some Theory of Inverse Demand for Applied Demand Analysis" European Economic Review 14:281-290.

Bäer, Danielle, Nicolai V. Kuminoff, Eric Van Buren, and Scott Van Buren. 2014. “Air Pollution Avoidance Behavior: National Evidence from EPA’s Air Quality Index” unpublished paper, Arizona State University, March.

Baker, Kirk, Heather Simon, Gobeail McKinley, Neal Fann, Elizabeth Chan, 2018. "Evaluating Reduced-Form Modeling Tools For Simulating Annual Average PM2.5 Impacts” U.S. Environmental Protection Agency, power point presentation, October. 
Borenstein, Severin, James Bushnell, Frank A. Wolak, and Matthew Zaragoza-Watkins. 2015. “Expecting the Unexpected: Emissions, Uncertainty and Environmental Market Design” NBER Working Paper no. 20999, March.

Brajer, Victor, Jane V. Hall, and Frederick W. Lurmann. 2010. "Valuing Health Effects: The Case of Ozone and Fine particles in Southern California.” Contemporary Economic Policy, 29 (4):524-535.

Carbone, Jared C. and V. Kerry Smith.2008. "Evaluating Policy Interventions with General Equilibrium Externalities,” Journal of Public Economics, 92: 1254-1274.

Chan, Nathan W. and Casey J. Wichman. 2018. “ The Effects of Climate on Leisure Demand: Evidence from North America” unpublished paper, Resources for the Future, March.

Chavas, Jean-Paul. 1984. "The Theory of Mixed Demand Functions.” European Economic Review, 24(3): 321-344.

Chavas, Jean-Paul and Daniel Mullarkey. 2002. "On the Valuation of Uncertainty in Welfare Analysis.” American Journal of Agricultural Economics, 84(1): 23-38.

Chetty, Raj. 2006. “A New Method for Estimating Risk Aversion.” American Economic Review, 96(5): 1821-1832.

Cohen, Alma and Liran Einav. 2007. “Estimating Risk Preferences from Deductible Choices” American Economic Review, 97 (3): 745-788.

Cropper, Maureen, Arthur Fraas, and Richard Morgenstern. 2017. "Looking Backward to Move Regulations Forward: Rigorous Ex Post Analyses Can Improve Regulatory Policies.” Science, 355(6332): 1375-1376.

Currie, Janet and Matthew Neidell. 2005. “Air Pollution and Infant health: What Can We Learn from California’s Experience?” Quarterly Journal of Economics, 120 (3): 1003-103 
Currie, Janet and Hannes Schwandt. 2016. "Mortality Inequality: The Good News from a County-Level Approach.” NBER working paper \#22199, April.

Deryugina, Tatyana, Garth Heutel, Nolan H. Miller, David Molitor, and Julian Reif. 2016. “The Mortality and Medical Costs of Air Pollution: Evidence from Changes in Wind Direction.” NBER Working Paper no. 22796, November.

Foster, William and Richard E. Just. 1989. “Measuring Welfare Effects of Product Contamination with Consumer Uncertainty.” Journal of Environmental Economics and Management,17 (3):266-283.

Fowlie, Meredith and Nicholas Z. Muller. 2017. "Market-based Emissions Regulation When Damages Vary across Sources: What Are the Gains from Differentiation? Unpublished working paper, Department of Agricultural and Resource Economics, University of California, Berkeley, February 11.

Gollier, Christian. 2001. The Economics of Risk and Time (Cambridge, Massachusetts: The MIT Press)

Graff Zivin, Joshua and Matthew Neidell.2009. “Days of Haze: Environmental Information Disclosure and Intertemporal Avoidance Behavior” Journal of Environmental Economics and Management, 58: 119-128.

Graff Zivin Joshua, Matthew Neidell, and Wolfram Schlenker. 2011. “Water Quality Violations and Avoidance behavior: Evidence from Bottled Water Consumption” American Economic Review: Papers and Proceedings, 101(3): 448-453.

Hafstead, Marc, Gilbert E. Metcalf, and Roberton C. Williams III. 2016. “Adding Quantity Certainty to a Carbon Tax.” Resources for the Future discussion paper DP16-43,October.

Kriström, Bengt J. and P. Riera. 1996. "Is the Income Elasticity of Environmental Improvements Less Than One?” Environmental and Resource Economics,7 (1):45-55 
Meyer, Donald J. and Jack Meyer. 2005. “Relative Risk Aversion: What do We Know?’ Journal of Risk and Uncertainty, 31(3):241-262.

Muller, Nicholas Z. 2011. "Linking Policy to Statistical Uncertainty in Air Pollution Damages." The B. E. Journal of Economic Analysis \& Policy, 11, 32.

Palmquist, Raymond B. 2005. "Weak Complementarity, Path Independence, and the Intuition of the Willig Condition.” Journal of Environmental Economics and Management, 49(1): 103-115.

Phaneuf, D. J., and V. Kerry Smith, 2005. “Recreation Demand Models”. In Handbook of Environmental Economics, Vol. 2, Valuing Environmental Changes, edited by K-G. Maler and J.F. Vincent. Amsterdam, Netherlands: North Holland, Chapter 15.

Shafran, Aric P., 2014. “Equivalent Option Price with Supply Uncertainty” Bulletin of Economic Research, 66(S1):S1-S16.

Shimshack, Jay P., Michael B. Ward, and Timothy K.M. Beatty.2007. "Mercury Advisories, Information, Education, and Fish Consumption” Journal of Environmental Economics and Management, 53: 158-179.

Smith, V. Kerry. 1992. “Arbitrary Values, Good Causes, and Premature Verdicts.” Journal of Environmental Economics and Management, 22(1):71-89.

Smith, V. Kerry and H. Spencer Banzhaf. 2007. “Quality Adjusted Price Indexes and the Willig Condition.” Economics Letters. 94(1):43-48.

Smith, V. Kerry, William H. Desvousges, and John W. Payne. 1995. "Do Risk Information Programs Promote Mitigating Behavior?” Journal of Risk and Uncertainty, 10:203-221.

Turnovsky, Stephen J., Haim Shalit, and Andrew Schmitz. 1980. "Price Instability and Consumer Welfare.” Econometrica, 48(1): 135-152.

Weitzman, Martin L. 1974. “Prices vs. Quantities”, Review of Economic Studies, 41 (4): 477491. 
Willig, Robert D. 1978. "Incremental Consumer Surplus and Hedonic Price Adjustment.” Journal of Economic Theory, 17 (2): 227-253. 